Original Research Paper

\title{
Removal of Coliform Content in Sewage Treatment Plant Using a Sand Filtration System with Potassium Permanganate Powder
}

\author{
${ }^{1}$ Sona Pazdar, ${ }^{2}$ Saeid Eslamian, ${ }^{2}$ Seyedeh Zahra Hosseini-Teshnizi, \\ ${ }^{3}$ Kaveh Ostad-Ali-Askari, ${ }^{3}$ Hossein Gholami, ${ }^{4}$ Shahide Dehghan, \\ ${ }^{2}$ Majedeh Haeri-Hamedani, ${ }^{5}$ Mohsen Ghane and ${ }^{6}$ Vijay P. Singh \\ ${ }^{1}$ Department of Civil Engineering, Aghigh University, Shahinshahr, Isfahan, Iran \\ ${ }^{2}$ Department of Water Engineering, College of Agriculture, Isfahan University of Technology, Isfahan, Iran \\ ${ }^{3}$ Department of Civil Engineering, Isfahan (Khorasgan) Branch, Islamic Azad University, Isfahan, Iran \\ ${ }^{4}$ Department of Geography, Najafabad Branch, Islamic Azad University, Najafabad, Iran \\ ${ }^{5}$ Civil Engineering Department, South Tehran Branch, Islamic Azad University, Tehran, Iran \\ ${ }^{6}$ Department of Biological and Agricultural Engineering and Zachry Department of Civil Engineering, \\ Texas A and M University, 321 Scoates Hall, 2117 TAMU, College Station, Texas 77843-2117, USA
}

Article history

Received: $26-10-2018$

Revised: $16-02-2019$

Accepted: 26-06-2019

Corresponding Author:

Sona Pazdar

Department of Civil

Engineering, Aghigh

University, Shahinshahr,

Isfahan, Iran

Isfahan, Iran

Email: sona.pazdar2011@gmail.com

\begin{abstract}
Reuse of refined sewage with two goals of providing more water and protecting the environment from pollution is one of the solutions to water supply problems and one of the potential sources for irrigation in agriculture. The aim of this study is to evaluate the possibility of effluent disinfection using a sand filtration system to reduce microbial contamination with potassium permanganate powder. Each experiment was performed in 3 replications. The results of this study showed that adding 5 weight percent of potassium permanganate powder to silica sand eliminates the removal efficiency of total coliform and focal coliform to $99.99 \%$. By reducing this percentage to 0.15 weight percent of potassium permanganate powder as the optimal amount, the results were the same. Also, the addition of 15 weight percent of potassium permanganate powder with silica sand increased the amount of opacity removal and the removal efficiency was $95.5 \%$. As measured parameters were less than environmental standards. According to the results, the performance of potassium permanganate powder with silica sand is better than other treatments.
\end{abstract}

Keywords: Wastewater, Total Coliform, Focal Coliform, Opacity, Potassium Permanganate, Removal Percentage

\section{Introduction}

Sewage or wastewater is consumed in which its physical, chemical or biological properties have changed to a degree that has lost its capacity for consumption at its best. Obviously, the amount of sewage in different industries is different. It depends on several factors, especially the type of process, raw materials, production and management. Lack of adequate monitoring of the quality of wastewater from sewage treatment plants in the country has caused the materials to be unprocessed and unprocessed in the majority of cases and cause significant damage to natural resources. A variety of fecal coliforms among the bacteria present in the sewage system are less likely to survive than viruses (Eslamian, 2015).
One of the main indicators in the application of refined sewage in irrigation is the concentration of fecal organisms and coliform bacteria. A World Health Organization expert meeting in 1973 stated that the production of 1000 coliforms in 100 milliliters would be technically easy and unrestricted irrigation of products with this kind of waste water would probably result in very limited health risks (Hajjami et al., 2012).

In Iran, during the Safavid period, Human waste was used as a fertilizer in the marginal lands of Isfahan. Sewage of many old townhouses was drained into streams called "Great creek", which were used to irrigate agricultural land. Sand filtration can reduce the need for chemicals for disinfection, also the cost of installing, repairing and maintaining them, it can be 
a good option in terms of economic justification (Farzadkia et al., 2009).

Arccivala (1991) showed that TDS, lead, chromium and cadmium are present more than permissible limits in drinking water at some stations in research. The TDS obtained in the domestic sewage in Indian cities was generally $400 \mathrm{mg} / \mathrm{L}$.

High Rate Transpiration System (HRTS) is one of the technologies that can be used for domestic effluent disposal and reuse. This hypothesis was tested in field and laboratory experiments conducted by the National Environmental Engineering Research Institute (NEERI), Nagpur, India (Thawale et al., 2006).

\section{History of Previous Studies}

Human beings have been using wastewater and sewage in agriculture many years ago. If the treated water has these characteristics it can be used to irrigation of vegetables: 1. Sewage treatment process is well done, 2. the industrial wastewater does not penetrate into it, 3 . it hasn't any heavy metal contamination and 4 . There is no limitation in terms of the health index. In these uses, the health index is very important.

Tabatabaei and Liaghat (2004) indicated that the concentration of heavy metals, chloride and sulfate ions in groundwater resources in southern and southeastern parts of Shiraz exceeds the limit for use in irrigation. According to the results, soybean and corn irrigation have a significant increase in performance compared to well water, but parsley irrigation with well water has no significant increase in performance. Cadmium accumulation in soybean and corn in sewage was not significantly different from well water (Petygrove and Asano, 1990). The results indicate the qualitative limitations of the flow of Firoozabad River from heavy metals and organic materials (DOH, 2017). Sadar (1996) showed that the ability of different species to absorb and accumulate of cadmium in different organs and the ability of most broadleaf leafy vegetables to absorb and accumulate of cadmium in various organs, especially the edible parts. Newcombe and Macdonald (1991) showed that irrigation with wastewater over a period of 9 years reduced the bulk density and permeability. It also increased moisture content in the field capacity, performance and quality of the crop compared with the irrigated field with effluent. It was observed that the concentration of 6-capacity chromium in water in some of the stations was more than the standard of Iran and the World Food Organization (FAO), but the amounts of lead, copper, cadmium, chromium, nickel and zinc were generally less than or equal to Recommended values (APHA, 1995). According to the results, reuse of effluent of sewage treatment plant in Mashhad in agriculture and its replacement with crop wells in urban use can be considered as a way to reduce the problem of the city (MDW, 2002). The results show that the quality parameters of wastewater except bicarbonate, nitrogen and total phosphorus are in the permitted range for irrigation of green space (Hajjami et al., 2012; Todar, 2007). Escherichia coli (2012) showed that nitrogen, phosphorus, potassium and salts of soluble wastewater are at the limit of agricultural land use, but it is necessary to reduce suspended solids, phosphorus and nitrogen in underground waters to discharge them. Also, nitrogen, chlorine, sodium and especially sodium bicarbonate are high in comparison with the FAO standard and it can be harmful depending on irrigation and plant type (Escherichia coli, 2012). Applying correct management such as increase in irrigation efficiency, optimal use of fertilizer and poison and change in irrigation methods have been suggested as effective factors in reducing the pollution of wastewater, as well as solutions including the use of natural and artificial pools, marshes Retaining tapes, herb canals, soil and grass filters and wastewater quality adaptation as effective strategies for reducing contamination in fields (Lucena et al., 2004). Bouwer et al. (1980) showed that the most important effect of these drains on the quality of water of the Zayandehrud River is increasing the water salinity of this river. Increasing salinity is to a large extent the water quality of this river is unusable for all users. showed that irrigation with wastewater reduced the saturated hydraulic conductivity and increased the bulk density of soil. Irrigation method has a significant effect on decreasing the ultimate penetration velocity of water in soil and decreasing the amount of the soil porosity The amount of nitrate in $90 \%$ of the wells was more than standard, but the concentration of heavy metals exception of cobalt is less than the standard of agricultural use According to the results, the concentration of heavy metals in soil and plant samples in irrigated fields with wastewater is slightly higher than their values in irrigated fields with well water. However, there was no limitation on the number of heavy elements in the irrigation of these plants with sewage the concentration of fat and oil parameters, suspended solids, COD, chlorine and sulfate chemical oxygen demand was higher than the standard for discharging into the environment, but the biochemical oxygen demand of $\mathrm{BOD}, \mathrm{Cd}, \mathrm{Pb}$ and $\mathrm{Zn}$ is lower than Iran's environmental standards According to the results, accumulation of lead, cadmium, copper, nickel and cobalt in plant organs is less than the standard and mixing ratio of $25 \%$ of raw sewage and $75 \%$ of well water is suggested as the best mixing ratio in terms of heavy metals accumulation (Eslamian, 2015), The results showed that by increasing the organic matter content in the wastewater used in irrigation of tomato, parsley and carrot plants, the amount of organic matter is increased (Eslamian, 2015), It was observed that the treatment of leakage irrigation with sewage was the most 
contaminated conditions. The use of subsurface drip irrigation method was recommended in terms of reutilization of urban sewage effluent It was observed that seven years of irrigation with effluent has been able to convert saline and sodium salts of the area into a suitable soil for agriculture without any other treatment. The soluble sodium and exchangeable sodium salts and the total amount of sodium are reduced to a large extent. Irrigation with wastewater has not been able to bring the concentration of heavy elements to the harmful border Proper use of wastewater and the role of soil and land in the treatment of sewage is a positive factor It illustrates the benefits of stabilization ponds and their role in the reuse of wastewater and provides its design bases for using wastewater in agriculture It was observed that the use of effluent has increased the yield of these plants compared with the control. It also had no negative effect on soil properties and especially its permeability in any of the treatments. There was no significant difference between treatments in terms of quality and accumulation of heavy metals. For health reasons, irrigation with effluent for carrot and lettuce is not recommended but it is recommended for tomatoes and cucumbers irrigation It was observed that $\mathrm{pH}$ and electrical conductivity of soil (EC) increased after irrigation compared to the preirrigation conditions with wastewater. It was also shown that the rate of most pollutants in Tehran's refinery is out of standard that it cannot be used for forest trees irrigation or re-use in the refinery It was observed that the use of effluent increased the yield. Also increased the accumulation macro and micro nutrients in the air organs of cucumber and carrot and also increased the concentration of macro and microelements in the soil. Also, the use of sewage increased the microbial contamination in the product The results showed that the use of sewage for irrigation of experimental fields increased the yield and concentration of macro and micronutrients in all the air and ground organs of tomatoes and carrots. It had no adverse effects on soil properties.

The land treatment system has an economic justification for sewage treatment when enough land is available with reasonable price. This method has the advantages of reducing the treating operations, reducing the number of workers and reducing the need for energy compared to commonly filtration systems and disadvantages such as the need to use a wider area of land than other filtration systems and not to use for areas with cold and humid air conditions, low soil permeability, shallow depth of surface, impermeable layer and topographic conditions with high slope

There several methods involved in the wastewater treatment such as Waste stabilization pond, Constructed wetland and Disinfection. The constructed wetland is currently the method adopted in many of developing countries. Constructed wetland is used as a method of wastewater treatment in order to improve water quality but if planned and maintained well - constructed wetland can promote water reuse like fish farming and irrigation for public benefits

Although irrigation with wastewater is a source of beneficial effects if its harmful effects do not well control, the disadvantages of using them are more than its beneficial effects. There is very little information on the effects of this irrigation on the physical and chemical properties of the soil and secondly, the quality of wastewater from each factory was different (Tabatabaei and Liaghat, 2004).

Today, because of the lack of available water resources, especially for agricultural purposes, reuse of sewage, in addition to preventing water pollution, eliminates many of the problems of water scarcity. Also, gaining adequate water resources and the effective and cost-effective removal of pathogens, chemicals and other water pollution is a growing global challenge (Farzadkia et al., 2009).

\section{Materials and Methods}

In order to investigate the reduction of the coliform of wastewater of treatment plant using a sand filtration system along with potassium permanganate powder. Also, the assessment of the quality of wastewater by chemical additives used in this study was carried out.

\section{Location and Time of Testing}

The research was carried out at the site of the municipal wastewater treatment plant in the city of Aligudarz (Arccivala, 1991). The location of the road of the village of Sanj in spring and summer in 2016 was as follows. The wastewater treatment system has been designed in 2016. It is similar to the wastewater treatment system in many cities in Iran.

The potassium permanganate powder that used in this experiment was a kind of industrial type and it was mixed with a specified percentage of silica sand. The Fig. 1 shows the Potassium permanganate powder. Characterized by oxidability, convenience for dosing, etc, potassium permanganate is used widely in drinking water treatment, industrial wastewater treatment, urban sewage treatment, groundwater treatment, soil remediation and atmospheric pollution control. Potassium permanganate, or $\mathrm{KMnO} 4$, is a common inorganic chemical used to treat drinking water for iron, manganese and sulfur odors. It can be used as a disinfectant as well, keeping drinking water free of harmful bacteria. Potassium permanganate is commonly used to remove them. Potassium permanganate oxidizes iron and manganese, causing the metals to precipitate out of the solution. 
Table 1: Research treatments and tested materials

\begin{tabular}{ll}
\hline Number of treatment & Tested materials \\
\hline 1 & silica sand (control treatment) \\
2 & silica sand plus 5\% potassium permanganate powder \\
3 & silica sand plus $2 \%$ potassium permanganate powder \\
4 & silica sand plus 1\% potassium permanganate powder \\
5 & silica sand plus $0.5 \%$ potassium permanganate powder \\
6 & silica sand plus $0.25 \%$ potassium permanganate powder \\
7 & silica sand plus $0.15 \%$ potassium permanganate powder \\
8 & silica sand plus $0.1 \%$ potassium permanganate powder \\
\hline
\end{tabular}

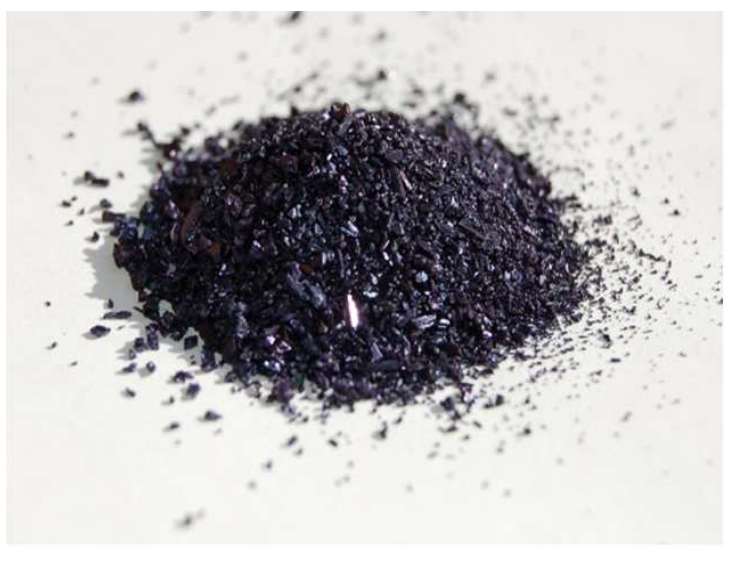

Fig. 1: Potassium permanganate powder

The samples were made in cylindrical tubes made of plastic with a diameter of about $14 \mathrm{~cm}$ and the height of $50 \mathrm{~cm}$. 8 treatments were prepared. For irrigation, lysimeters were used from the effluent of the treatment plant. A lysimeter is a measuring device which can be used to measure the amount of actual evapotranspiration which is released by plants (usually crops or trees). By recording the amount of precipitation that an area receives and the amount lost through the soil, the amount of water lost to evapotranspiration can be calculated.

Research treatments including silica sand, potassium permanganate powder are presented in the Table 1 .

Silica sand is used in many commercial processes and products. Therefore, is commonly classified on the basis of industrial applications. The major industrial uses of siolica sand can be categorized as follows: building products, glassmaking, hydraulic fracturing, refractory agent and etc.

\section{Results}

In this paper, wastewater disinfection has been evaluated using sand filtration system along with potassium permanganate powder in the removal of coliforms. Table 2 the results of the coliform of the wastewater sample before the filter are shown in various repetitions.

The above table shows the results of the Second and third repetition in the supplementary step is different from another steps because the number of coliforms with 3 reparative is $46^{*} 10^{3} \frac{M P N}{100 M L}$ rather than another method which is $24 * 10^{3} \frac{M P N}{100 M L}$. In this experiment, the results were the same in all three cultivated tubes of the possible step and confirmation step. All results of three cultivated tubes were positive in each dilution which indicates a high number of total coliforms. In the supplementary step, which is related to the diagnosis of the number of focal coliforms, the second repeat and the third repeat are the same and it was slightly different from the first repeat. To increase accuracy, the second and third repetition numbers were considered as final data.

In experiments that were carried out from the effluent after the passage of the control filter, which included only silica sand, the results of the coliforms were observed according to Table 3 .

The above table shows the results of the number of positive tubes in a 3-pipe method which the number of coliforms with 3 repetitive is $11 * 10^{4}, 24 * 10^{3}$ and $46^{*} 10^{2}$ $\frac{M P N}{100 M L}$, respectively. In the wastewater experiments after the control filter, in the second and third repetitions, the results were the same with the first step. Regarding the significance of the test results to the pre-filter effluent sample experiments, the comparison chart of the total coliform and focal coliform in Fig. 2 and 3 is shown.

The Fig. 2 shows 3 samples of the number of Coliforms which sample wastewater before filtering is highest number of coliforms and the lowest number of coliforms is sample wastewater after filter with permanganate powder.

The Fig. 4 shows the sample wastewater before filtering is the highest number of focal coliforms. And the sample wastewater after filter with permanganate powder is the lowest number of focal coliforms.

The Fig. 5 shows the number of focal coliforms for sample wastewater before filtering as equal as sample wastewater after control filter, but the lowest number of focal coliforms is sample wastewater after filter with permanganate powder.

According to the environmental organization standard, the total amount of coliforms is lower than the standard and the amount of focal coliform is in accordance with the standard. 


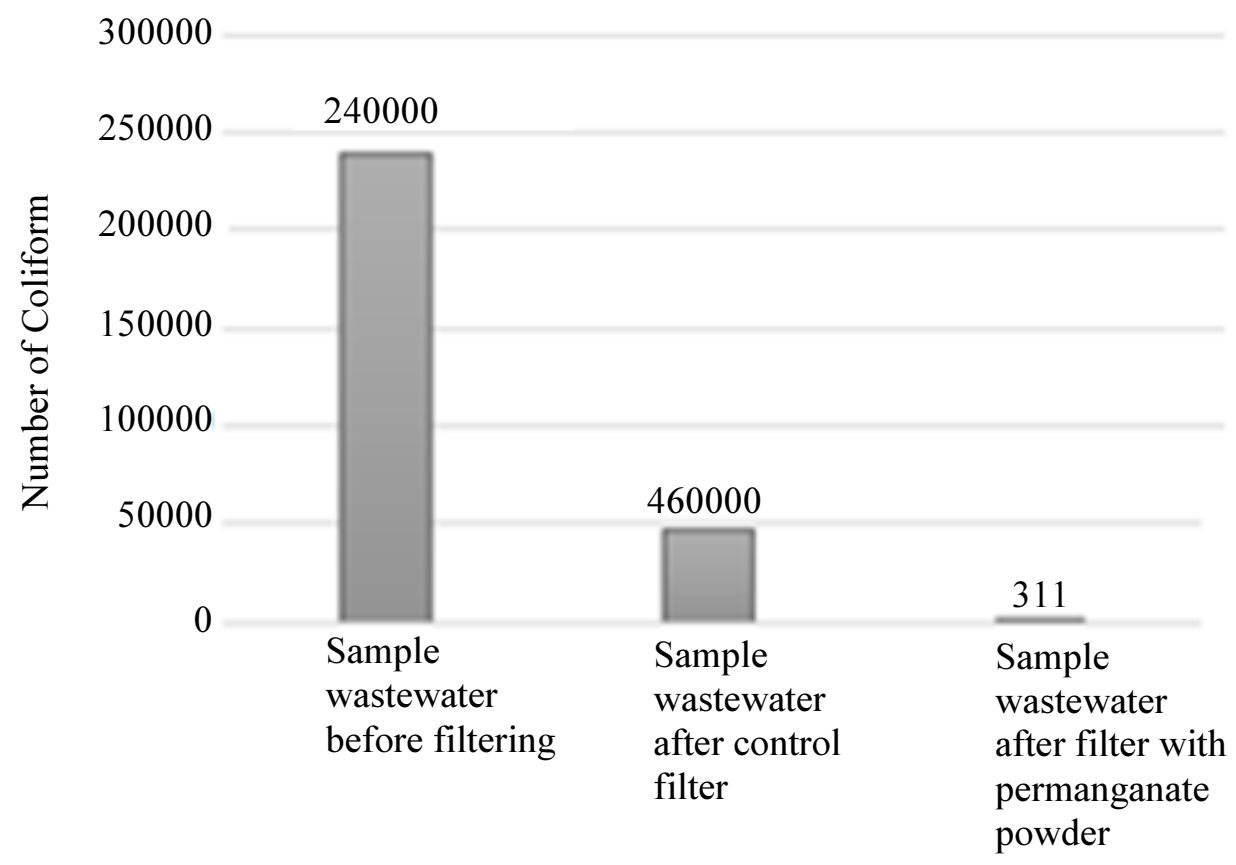

Samples

Fig. 2: The total number of total Coliform after the control filter compared to the pre-filter effluent

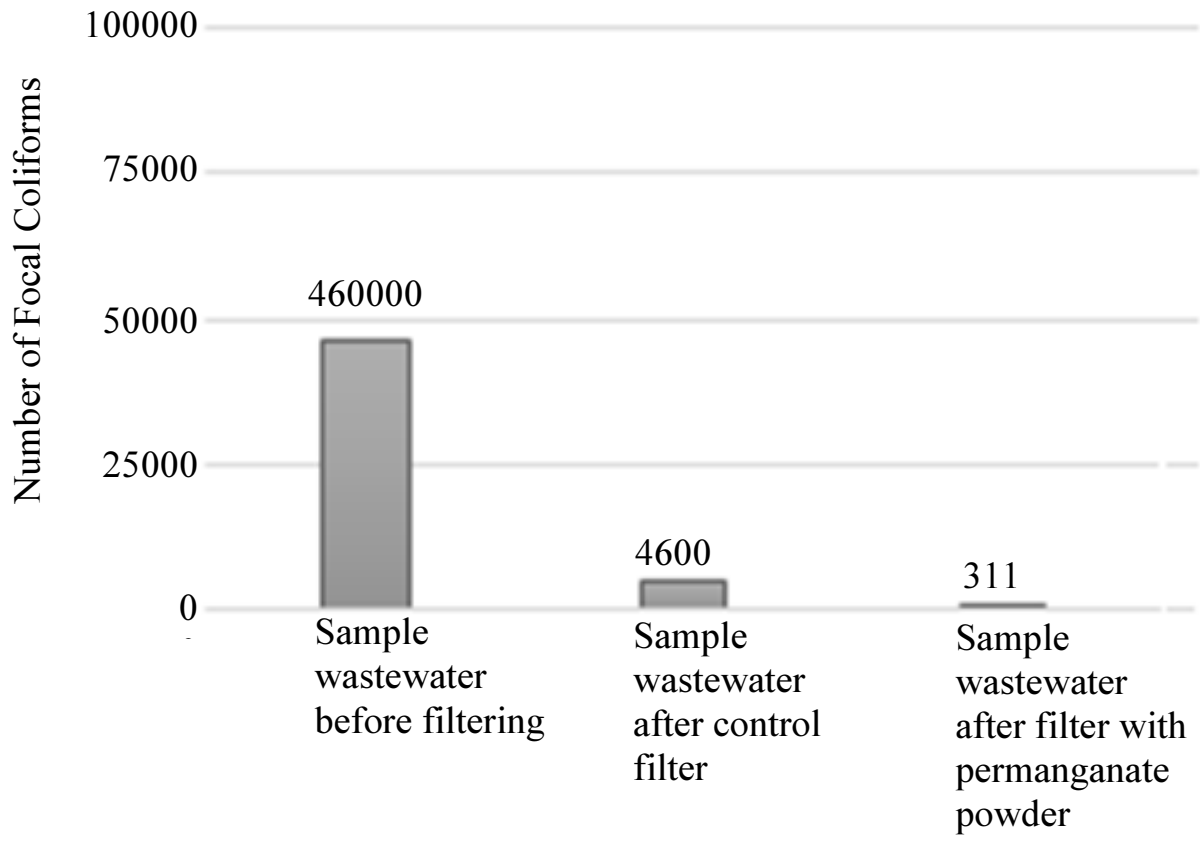

Samples

Fig. 3: The number of Focal Coliform after the control filter compared to the pre-filter effluent 


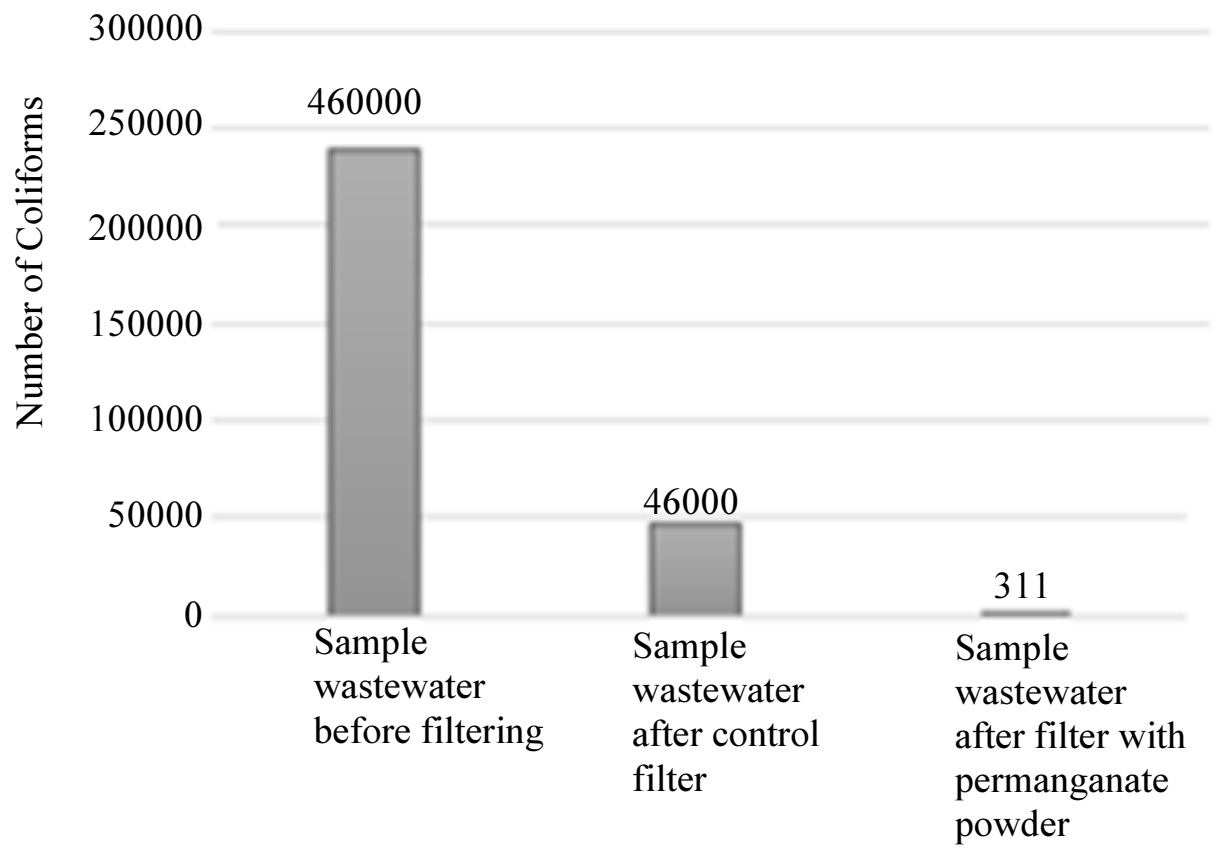

Samples

Fig. 4: The number of total Coliform after filtering with permanganate powder compared to the pre-filter effluent

100000

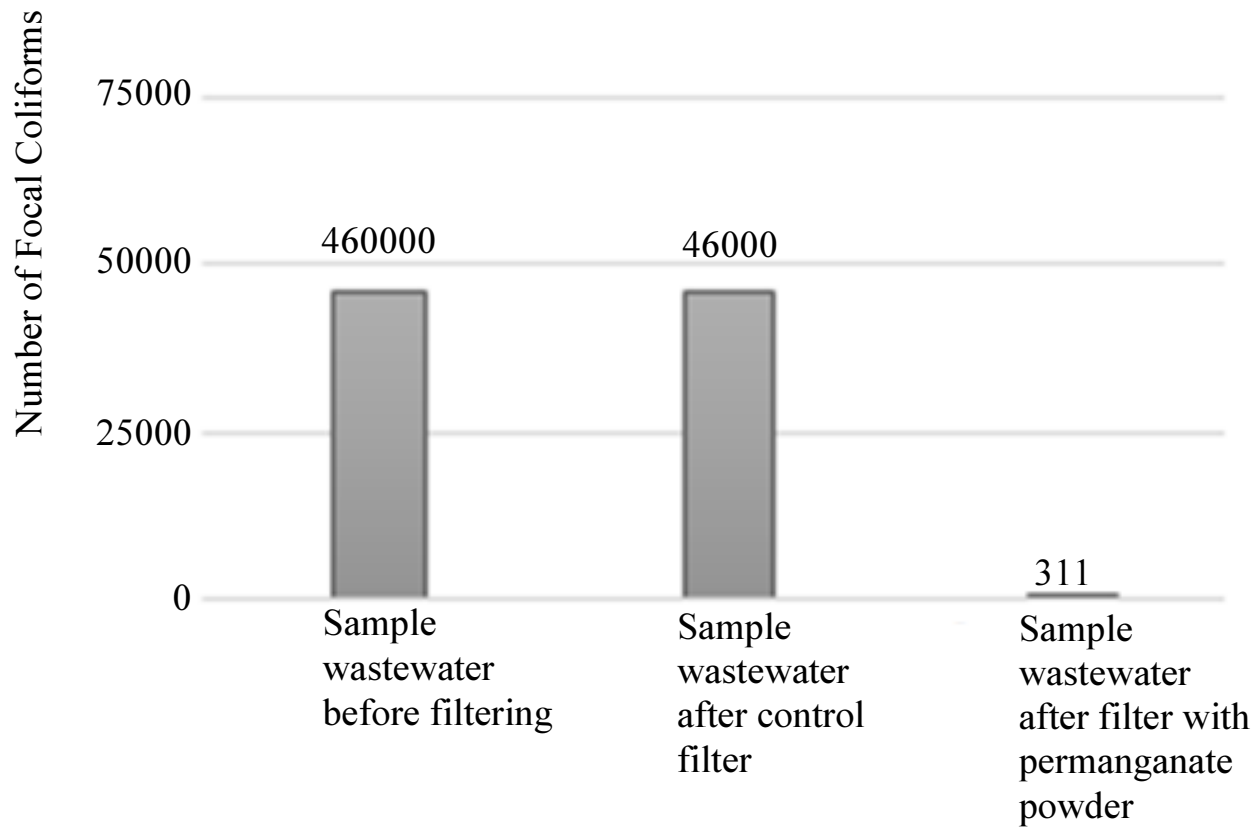

Samples

Fig. 5: The number of Focal Coliform after filtering with permanganate powder compared to the pre-filter effluent 
Table 2: The results of the coliform for the sample of the waste water before filtering

The number of positive reaction tubes in a 3-pipe method

\begin{tabular}{lllll} 
Dilution & $0.001 \mathrm{~mL}$ & $0.01 \mathrm{~mL}$ & $0.1 \mathrm{~mL}$ & $\begin{array}{c}\text { The number of coliforms } \\
\text { with } 3 \text { reparative } \frac{M P N}{100 M L}\end{array}$ \\
\hline Repeat the first, second and third possible steps & 3 & 3 & 3 & $24 * 10^{4}$ \\
Repeat the first, second and third confirmation steps & 3 & 3 & 3 & $24 * 10^{4}$ \\
Repeat the first supplementary step & 0 & 3 & 3 & $24 * 10^{3}$ \\
Second and third repetitions in the supplementary step & 1 & 3 & 3 & $46^{*} 10^{3}$
\end{tabular}

(MPN/100 Ml means that the Most Probable Number of viable cells in $100 \mathrm{~mL}$ of sample)

Table 3: The results of the coliform of the wastewater sample after passing the control filter

The number of positive reaction tubes in a 3-pipe method

\begin{tabular}{lllll} 
Dilution & $0.001 \mathrm{~mL}$ & $0.01 \mathrm{~mL}$ & $0.1 \mathrm{~mL}$ & with 3 repetitive $\frac{M P N}{100 M L}$ \\
\hline Repeat the first, possible step & 2 & 3 & 3 & $11^{*} 10^{4}$ \\
Repeat the first confirmation step & 1 & 3 & 3 & $24^{*} 10^{3}$ \\
Repeat the first supplementary step & 0 & 1 & 3 & $46^{*} 10^{2}$ \\
\hline
\end{tabular}

(MPN/100 Ml means that the Most Probable Number of viable cells in $100 \mathrm{~mL}$ of sample)

Table 4: Sample of wastewater after filtering with $5 \%$ by weight of potassium permanganate powder

The number of positive reaction tubes in a 3-pipe

\begin{tabular}{lllll} 
Dilution & $0.001 \mathrm{~mL}$ & $0.01 \mathrm{~mL}$ & $0.1 \mathrm{~mL}$ & with 3 repetitive $\frac{M P N}{100 M L}$ \\
\hline Possible stage with three repetitions & 0 & 0 & 0 & $<300$ \\
\hline
\end{tabular}

(MPN/100 Ml means that the most probable number of viable cells in $100 \mathrm{~mL}$ of sample)

Sample Wastewater after Filter with Permanganate Powder

In this step, $300 \mathrm{~g}$ of potassium permanganate powder ( $5 \%$ by weight) was added to the topcoat filter containing the smallest particles of silica sand. After passing the wastewater and harvesting repeated samples, the results of the experiment were obtained according to Table 4.

The above table displays possible stage with three repetitions are zero, also the number of coliforms with 3 repetitions less than $300 \frac{M P N}{100 M L}$. According to the table listed in a 3-pipe method, all pipes were negative, meaning that there was a possibility of completely eliminating all microbial contamination. For this reason, to provide a more reliable answer, the environmental compositions were again tested with less dilution.

\section{Back to Less Dilution}

The following table illustrates repeat the first and second possible stages are 0 and 1 which the number of coliforms is $7 \frac{M P N}{100 M L}$. As shown in Table 5, with a return to less dilution and a re-test, the total number of total coliforms in this stage was determined for higher accuracy, the values for the first and second repeat were evaluated. Output efficiency is $99 / 99 \%$.
According to the mentioned materials and tests, the best way to reduce microbial contamination is to use a filter with potassium permanganate powder. But it is worth noting that the amount of permanganate can be reduced and the result is the same. Therefore, several experiments were carried out in the form of tests and errors to find the optimal amount of potassium permanganate powder:

- Silica sand plus 2 weight percent potassium permanganate powder

- Silica sand plus 1 weight percent of potassium permanganate powder

- Silica sand plus 0.5 weight percent of potassium permanganate powder

- Silica sand plus 0.25 weight percent of potassium permanganate powder

- Silica sand plus 0.15 weight percent of potassium permanganate powder

All of the treatments were tested according to the previous steps. Finally, silica sand plus 0.25 weight percent of potassium permanganate powder, with the same conditions in the filters, was similar to the results of using potassium permanganate powder with 5 weight Percent. In fact, $15 \%$ by weight and lower showed an inverse trend in the total number of coliforms. With the decrease in the amount of potassium permanganate, the 
total number of coliforms increased. The result of this step of the experiment is as follows:

More dilution was also made for the accuracy of the coliforms count.

As can be seen, the results are similar to $5 \%$ potassium permanganate treatment, which is $99.99 \%$ of the total removal efficiency of the total coliforms. Finally, the eighth test, which is 0.15 weight percent of potassium permanganate, was obtained according to Table 8 .

Although the results of this stage were also in accordance with the standard, the lower the microbial contamination in wastewater quality is certainly more important for different applications. Therefore, in the present study, seventh treatment, which is a filter with 0.25 weight percent of potassium permanganate, has been identified as the best removal efficiency of microbial contamination.

Figure 6, a comparison of the effect of weight percentages of potassium permanganate powder on the removal efficiency was made.
The Fig. 6 Illustrates five weight percentages of potassium permanganate are the same percentage of removal efficiency and $0.15 \%$ of the weight percentages of potassium permanganate is $99 \%$ of the percentage of removal efficiency.

Table 6 shows effluent after filtering with 0.25 weight percent of potassium permanganate powder that it is done three various dilution $(0.01,0.01,0.1 \mathrm{ml})$ and the result of possible stage (Diution $=0.01,0.1 \mathrm{ml}$ ) both of them are equal 1 and larger than possible stage (dilution=0.001) which is equal zero. It is a result effluent after filtering with 0.25 weight percent of potassium permanganate powder with the number of coliforms (70 MPN/100ML). it shows the important of amount of coliform in the result of effluent with 0.25 weight percent of potassium permanganate powder. Table 7 displays the Dilution for the accuracy of the coliforms count less than $300 \mathrm{MPN} / 100 \mathrm{ML}$ for three different Dilution that the result of all possible stage of them are zero.it also shows the effect of number of coliforms (less than $300,<300 \mathrm{MPN} / 100 \mathrm{ML}$ ) rather than other amount of the coliform (7, $70 \mathrm{MPN} / 100 \mathrm{ML})$.

Table 5: Repeat the test with less dilution

The number of positive reaction tubes in a 3-pipe

\begin{tabular}{llccc} 
Dilution & $0.001 \mathrm{~mL}$ & $0.01 \mathrm{~mL}$ & $0.1 \mathrm{~mL}$ & The number of \\
\hline Repeat the first and second possible stages & 0 & 1 & 1 & 7
\end{tabular}

(MPN/100 Ml means that the most probable number of viable cells in $100 \mathrm{~mL}$ of sample)

Table 6: Sample of effluent after filtering with 0.25 weight percent of potassium permanganate powder

The number of positive reaction tubes in a 3-pipe

\begin{tabular}{|c|c|c|c|c|}
\hline Dilution & $0.001 \mathrm{~mL}$ & $0.01 \mathrm{~mL}$ & $0.1 \mathrm{~mL}$ & coliforms $\frac{M P N}{100 M L}$ \\
\hline Possible stage & 0 & 1 & 1 & 70 \\
\hline
\end{tabular}

(MPN/100 Ml means that the most probable number of viable cells in $100 \mathrm{~mL}$ of sample)

Table 7: More dilutions for the accuracy of the coliforms count

The number of positive reaction tubes in a 3-pipe

\begin{tabular}{lllll} 
Dilution & $0.001 \mathrm{~mL}$ & $0.01 \mathrm{~mL}$ & The number of \\
\hline Possible stage & 0 & 0 & 0 & coliforms $\frac{M P N}{100 M L}$ \\
\hline
\end{tabular}

(MPN/100 Ml means that the most probable number of viable cells in $100 \mathrm{~mL}$ of sample)

Table 8: Sample of effluent after filtering with 0.15 weight percent of potassium permanganate powder The number of positive reaction tubes in a 3-pipe

\begin{tabular}{lllll} 
Dilution & $0.001 \mathrm{~mL}$ & $0.01 \mathrm{~mL}$ & $0.1 \mathrm{~mL}$ & $\begin{array}{c}\text { The number of } \\
\text { coliforms } \frac{M P N}{100 M L}\end{array}$ \\
\hline Repeat the first, possible & 1 & 1 & 1 & 1100 \\
Repeat the first confirmation & 0 & 0 & 0 & 400 \\
Repeat the first supplementary step & 0 & 0 & 0 & $<300$ \\
\hline
\end{tabular}

(MPN/100 Ml means that the Most Probable Number of viable cells in $100 \mathrm{~mL}$ of sample) 


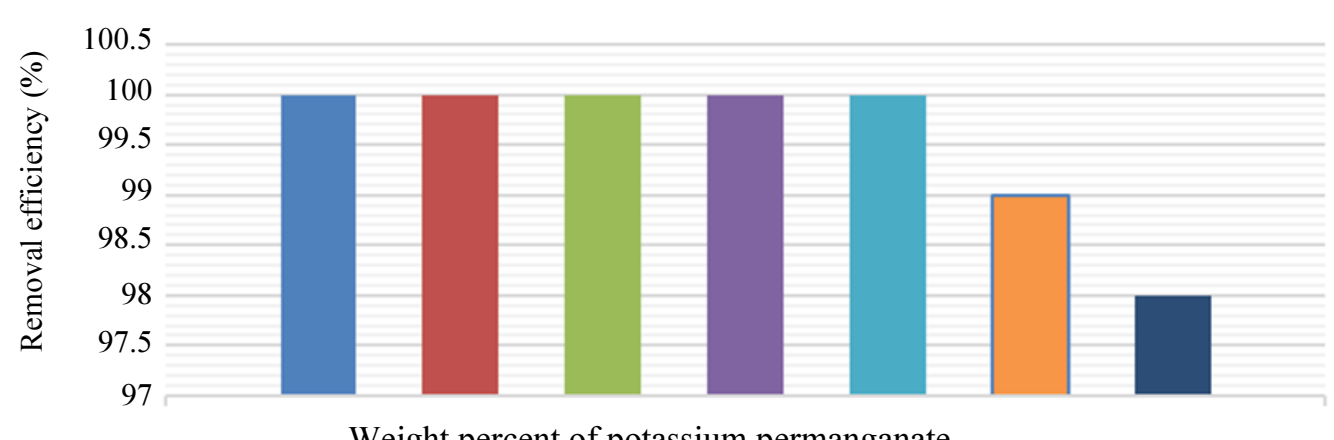

Weight percent of potassium permanganate

Weight percentages of potassium permanganate: $\because 5 \quad \square=2 \quad \square=0 / 5 \quad 0 / 25 \square 0 / 15 \square 0 / 1$

Fig. 6: Removal efficiency of total coliform with changes in weight percentages of potassium permanganate

As can be seen, from 5 to 0.25 weight percent of potassium permanganate powder, the removal efficiency is $99.9 \%$. By decreasing weight percentages, the removal efficiency decreases so that with a weight loss of 0.15 weight percent, the removal efficiency is $98 \%$. Similarly, with lower percentages of potassium permanganate powder, the removal efficiency of the coliform is also reduced and falls outside the environmental standard.

\section{Conclusion}

Recycle of purified wastewater with two aims of preparing more water and preserving the surrounding from contamination is one of the solutions to water supply issues and one of the possible sources for irrigation in farming. The goal of this article is to assess the eventuality of effluent disinfection applying a sand filtration process to decrease microbial pollution with potassium permanganate powder. Any experience was done in 3 repetition. The consequences of this article displayed that adding 5 weight percent of potassium permanganate powder to silica sand removes the removal efficiency of total coliform and focal coliform to $99.99 \%$. In addition, increasing of 15 weight percent of potassium permanganate powder with silica sand enhanced the amount of darkness removal and the removal proficiency was $95.5 \%$. As determined criterions were less than environmental levels. Regard to the consequences, the implements of potassium permanganate powder with silica sand is superior to other behaviors. The present study was carried out in 8 treatments including the first treatment: silica sand (control treatment), second treatment: silica sand plus 5 weight percent potassium permanganate powder, third treatment: silica sand plus 2 weight percent potassium permanganate powder, fourth treatment: silica sand plus 1 weight percent of potassium permanganate powder, fifth treatment: silica sand plus 0.5 weight percent of potassium permanganate powder, 6th treatment: silica sand plus 0.25 weight percent of potassium permanganate powder, 7th treatment: silica sand plus 0.15 weight percent of potassium permanganate powder, 8th treatment: silica sand plus 0.1 weight percent of potassium permanganate powder.

\section{Acknowledgment}

This research was supported by the Isfahan University of the Technology. We thank our all authors who provided insight and expertise that greatly assisted the research.

\section{Author's Contributions}

All authors contributed to design the study, write and revise the manuscript.

\section{Ethics}

The present Study and ethical aspect were approved by the Isfahan University of the Technology. The present study was approved by the Isfahan University of Technology.

\section{References}

APHA, 1995. Standard Methods for the Examination of Water and Wastewater. 19th Edn., American Public Health Association, Washington.

Arccivala, S., 1991. Wastewater for Pollution Control. 1st Edn., Mc Graw-Hill. New Dehli, pp: 182.

Bouwer, H., R.C. Rice, J.C. Lance and R.G. Gilbert, 1980. Rapid-infiltration research at flushing meadows project, Arizona. J. Water Pollutant. Control Fed., 52: 2457-2470.

DOH, 2017. Noncommunity public water supply unit. Revised Total Coliform Rule Summary, Department of Health. 
Escherichia coli, 2012. CDC national center for emerging and zoonotic infectious diseases. Escherichia coli.

Eslamian, S., 2015. Urban Water Reuse Handbook. 1st Edn., Francis and Taylor, CRC Group, USA, ISBN-10: 1482229145, pp: 1177.

Farzadkia, M., N. Jaafarzadeh and L. Loveimi Asl, 2009. Optimization of bacteriological quality of biosolids by lime addition. Iran J. Environ. Health Scientific Eng., 6: 29-34.

Hajjami, K., M.M. Fouad, S. Oubrim, N. Khallayoune and N. Cohen, 2012. Assessment of helminths health risk associated with reuse of raw and treated wastewater of the Settat City (Morocco). Resources Environ., 2: 193-201.

DOI: $10.5923 /$ j.re.20120205.03

Lucena, F., A. Duran, A. Morón, E. Caldero and C. Campos et al., 2004. Reduction of bacterial indicators and bacteriophages infecting faecal bacteria in primary and secondary wastewater treatments. Applied Microbiol., 97: 1069-1076. DOI: $10.1111 / \mathrm{j} .1365-2672.2004 .02397 . x$

MDW, 2002. Water quality and public health. The Microbiology of Drinking Water, Department of the Environment.
Newcombe, C.P. and D.D. Macdonald, 1991. Effect of suspended sediments on aquatic ecosystems North American. J. Fisheries Manage., 11: 72-82.

DOI:

$10.1577 / 1548$ 8675(1991)011<0072:EOSSOA $>2.3 . \mathrm{CO} ; 2$

Petygrove, S. and T. Asano, 1990. Irrigation with reclaimed municipal wastewater - a guidance manual. California State Water Resources Control Board, Department of land, Air and water Resources.

Sadar, M.J., 1996. Understanding turbidity science. Hach Company Technical Information Series-Booklet.

Tabatabaei, S.H. and A. Liaghat, 2004. Use of zeolite to control heavy metal municipal wastewater applied for irrigation. Japanes Association Ion Exchange Press.

Thawale, P.R., A.A. Juwarkar and S.K. Singh, 2006. Resource conservation through land treatment of municipal wastewater. Nat. Eng. Res. Instit., 90: 5-15.

Todar, K., 2007. Pathogenic E. coli. Online Textbook of Bacteriology, University of Wisconsin-Madison Department of Bacteriology. 